\title{
Benefits and Barriers of Computer Assisted Language Learning and Teaching in the Arab World: Jordan as a Model
}

\author{
Nedal A. Bani Hani \\ Department of English Language and Literature, Irbid College, Al-Balqa- Applied University, Jordan
}

\begin{abstract}
The per se of this ad hoc research was to highlight the benefits and barriers of computer assisted language learning and teaching in the Arab World and Jordan in particular. The researcher constructed a questionnaire consisted of the advantages and disadvantages of utilizing computer in teaching languages in the world. The sample of the study contained 200 English language teachers in Jordan. The researcher used a twoscale questionnaire (agree and disagree). The researcher asked the participants to determine whether he or she agreed or disagreed on the provided items. The percentage for each item was computed to find out the most important benefits and barriers. The findings revealed that the most significant barriers were: (1) inadequate number of computers, (2) technical problems, (3) needs more teacher training, (4) more time is needed, (5) the cost is high. The results also showed that the most essential benefits were: (1) providing immediate feedback, (2) motivating students' learning, (3) exciting and more fun, (4) initiating more interaction, (5) easy to control. In conclusion, the researcher put forth some recommendations and solutions to tackle the barriers that emerged from this study.
\end{abstract}

Index Terms-CALL, barriers, benefits, TEFL, Arab world, Jordan

\section{INTRODUCTION}

Technology is now prevalent. It is utilized in every aspect of our life. The computer, having various pedagogical characteristics, has been utilized in teaching languages around the world. It affects the way we view teaching and learning, probably more than most educators admit. This led to the prominence of the Computer-Assisted Language Learning (henceforth CALL).Some methodologists maintain that the utilization of computer in the basic stage is the most beneficial for students. (See for example, Almekhlafi, 2006; Murphy, 2007; Bani Hani, 2009).

Moreover, there may be a de facto consensus that exists among most methodologists that the computer can only be a teaching tool and may never replace the teacher (cf., Levy 1997; Traynor, 2003; Noemi, 2007; Bani Hani, 2009; Gee, 2013). However, utilizing the computer requires establishing effective instructional programs. It is believed that the lack of efficient and authentic programs is frequently cited by teachers as a reason for their reluctance to incorporate computer-based learning techniques in their own classroom practice (Thelmadatter, 2007; Bani Hani, 2009). The researcher displays certain skepticism in teachers' inclination or ability to improve teaching. Consequently, the computer may be considered one of the visual aids that can be used to enhance students' learning and achievement in English. (Al-Ruz \& Khasawneh 2011:8).

It is worth noting that there may be a long tradition of using visual aids such as videos, projectors and language labs in the classroom to supplement and amplify teaching abilities and the computer can be deemed as the latest addition to this range of tools. The prominence of the computer makes it essential to acquire basic computer skills other than computer programming. In order to use computers for teaching, there are important apparatus that must exist in the classroom. Hardware and software are considered the most indispensable. The supply of hardware and software to schools is now sufficient for educational needs. Hardware is largely a matter of funding, and is beyond the scope of our discussion in this research.

In the Arab and Jordanian context, the Ministries of Education (MoEs) can not succeed if they do not know in which direction to move. They have always been reforming their educational systems but rarely improving. Improvement can not take place unless Arab and Jordanian teachers employ markedly more effective instructional methods. Moreover, teachers ought to be convinced that teaching can be studied and improved. In addition, they should be persuaded that there is always room for improvement; no matter how well our students are doing now; it is foolish not to try to improve. Because the future of education depends largely on what is happening in the classroom, therefore, this research comes into prominence to avoid counterreformation and counterproductivty.

Taking Jordan into consideration, the government has been subsidizing the Ministry of Education for the teaching of EFL by providing an authentic curriculum and feasible teacher training programs. Meanwhile, thousands of computers have been brought into our schools. Recently, 65,000 personal computers (PCs) have been installed in 2,250 public schools, bringing the ratio of student to PC from 43:1 in 2001 to 15:1 in 2004 (cited in Bataineh \& Baniabdelrahman, 2006:3). 
The utilization of computers in the classroom has proven advantageous in more than one respect. Not only has it been found to facilitate student learning, but it has also been found to develop students' ability to learn independently, analyze information, think critically, and solve problems (Goldman, Cole \& Syer, 1999; Smith, 2008). Al Abdel Halim (2009) reports significant increases in students' reading speed and comprehension across studies of computer-assisted reading instruction.

Following the same path, Noemi (2007) claims that even though they may never replace teachers, computers can provide excellent and fairly inexpensive supplementary materials to enhance classroom instruction. Furthermore, computers have been found not only to promote visual, verbal and kinesthetic learning, higher-level thinking, and problem solving (Turnbull \& Lawrence, 2002), but also to offer immediate feedback, hands-on learning, and collaborative instruction (see for example, Becker, 2000; Zapata, 2004; Noemi, 2007; Al Abdel Halim, 2009).

Consequently, the central focus of this research is to highlight the advantages and disadvantages of CALL implementation as perceived by Jordanian teachers. Knowing these advantages and disadvantages may be significant for helping the Jordanian Ministry of Education to move in the right direction towards reformation, innovation and improvement. Thus, one pushing impetus that lies behind conducting this research is to answer the following question: What are the advantages and disadvantages of the implementation of CALL in Jordan?

The researcher emphasizes that we must recognize both advantages and disadvantages of using computer so we can get the maximum effectiveness of technology to enhance foreign language learning. In light of the several current computer-related educational reforms in Jordanian institutions of learning, the results of the present study are expected to provide valuable information to bridge the gap in the literature about computer use in the third world countries, and the Arab world represented here by Jordan. The present study is also hoped to establish grounds for further research in this area. In addition, finding the advantages and disadvantages may be helpful in making decision i.e. to support the positive qualities and avoid the negative ones. However, the generalizability of the findings may be limited due to the fact that the present study focuses solely on Jordanian EFL teaching and learning. The data do not confirm that the respondents are indeed as proficient as they perceive themselves to be.

\section{THE LITERATURE REVIEW}

There are two types of factors that affect the implementation of computer in language teaching. They are external factors and internal ones. The benefits and barriers often emerge from these factors. Previous researches have indicated that both external and internal factors influence the computer use in education (Al-Ruz \& Khasawneh 2011; Lin, Wang \& Lin 2012; Sang, Valcke, Braak, Tondeur \& Zhu 2011; Tezci 2011). Among the external factors, the most common are access to computers and software, insufficient time for course planning, and inadequate technical and administrative support (Al-Ruz \& Khasawneh 2011). Among the internal factors, teachers' attitude, confidence, and belief in the computer use are commonly cited in the existing literature (Chen 2008; Al-Ruz \& Khasawneh 2011; Sang et al. 2011; Tezci 2011; Lin, Wang \& Lin 2012).

Moreover, the research appears to have identified all possible external and internal factors influencing the computer use (Al-Ruz \& Khasawneh 2011; Lin, Wang \& Lin 2012; Sang et al. 2011; Tezci 2011). However, there has been meager research into the possible relationships between external and internal variables, and how these relationships differ according to the variables involved in the computer integration. Examining these relationships could not only help teachers, students, and administrators understand the challenges of the computer use better, it could also assist them in uncovering other solutions to overcome the existing barriers based on the relationships among different variables. (Jonita, 2002; Traynor, 2003; Wright, 2003; Noemi (2007).

Han (2008) emphasizes that with the remarkable development of computers and Internet, more and more second language practitioners are utilizing computers for foreign language teaching and learning today. Although the use of computer in teaching and learning has a positive effect on the achievement levels of second language learners, there are still some barriers to the wide implementation of computers. This paper and from the historical perspective examines the different developing phases of computer assisted language teaching, and then basically, investigates the benefits and barriers of computers in language teaching and learning. The article maintains that language specialists must recognize both the benefits and limitations of using computers so that they can try their best to overcome the barriers and get the maximum effectiveness of technology to improve second language learning.

AbuSeileek \& Abu Sa'aleek (2012) argue that computer assisted language learning and teaching has entered to a new era, specifically with the emergence of microcomputer and the Internet. Computers can facilitate different learning tasks and have enormous potency as teaching aids. They can assist both students and teachers because of their special characteristics. This paper investigates the advantages and disadvantages of Computer-Assisted Language Learning (CALL) for current foreign language learning and teaching. The results imply that it is necessary to utilize computers in recent second language classroom, in spite of their demerits and weaknesses. Therefore, when we attempt to apply CALL programs to improve teaching or learning EFL, we have to recognize what the merits and demerits are in modern CALL programs so as to avoid misemploying CALL programs and get its maximum benefits for our EFL teaching and learning.

Koua (2012) emphasizes that the computer assisted learning technology, such as the internet, is deemed an ideal tool for language teaching and learning. It supports a learner-centered and functional approach to knowledge but may 
present an easy but also a culturally limited, learning medium. Only a few studies examine the net benefits of the internet and other computer technologies on students' intention to learn a romance language despite the controversy surrounding their use in mastering a language. The researcher examines the role of computer technology with emphasis on the internet and its associated media in the simplification of teaching and learning French employing a review of literature, anecdotes from students' class interaction to point out that the computer enhancing technology, like the internet, is a significant but controversial cultural and political instrument for teaching and learning the French language.

Riasati, Allahyar, and Tan (2012) claim that technology, especially e-learning technology, is being increasingly employed in instruction to enhance teaching and learning. This paper is basically a preliminary discussion of the advantages of and barriers to the use of technology in language instruction. Recognizing the benefits and barriers of technology integration is an essential step in integrating technology into education successfully. Lack of this knowledge may significantly impede stakeholders and educational centers from encountering the challenges of introducing and supporting the extensive use of technology by teachers in the classroom. Results from empirical research in this area, as well as implications for language practitioners have been included in the discussion.

$\mathrm{Fu}$ (2013) reported on the usage of information and communication technology (ICT) in education. Specifically, this article reviews researches that have investigated the merits of ICT integration in schools, barriers or challenges encountered in the use of ICT, factors affecting successful ICT integration, in-service and pre-service teachers' attitudes, perceptions, and confidence in utilizing ICT as well as the significance of school culture in the use of ICT. This review discusses gaps in the literature and the directions that future studies may follow in order to tackle these gaps.

To summarize, with the advent of the Internet and the associated technologies, the researcher advocates that English becomes an extraordinary significant instrument for international communication. Consequently, this will lead to axiomatic cultural interaction among different nations in the world. It is no doubt true; however, that CALL can be an adequate medium for improving the quality of teaching and learning the language. This is due to the following leverage points: (1) the computer may be suitable for provoking fruitful classroom activities which help in the acquisition of the four language skills, (2) CALL can help students learn inside as well as outside the classroom, (3) it may also provide individualized, continuous and authentic teaching activities, (4) it reduces learners' apathy and lack of involvement in the learning process. So, CALL supports the latest pedagogical theory which is learner-centered approach, (5) it may also be a tool for the integration of the four skills, and (6) the computer can provide learners with immediate feedback.

Nevertheless, none of the above should blind methodologists to the fact that teachers should not be neglected or replaced by the computer. On the contrary, CALL is calling for the establishment of rapport between the teacher and the computer. Therefore, it is downright risky to claim that the computer will delimit the role of the teacher in the language classroom but it will definitely change it.

As for the disadvantages of CALL, Levy (1997: 2) lists several criticisms of CALL use in the language classroom. The most important are: (1) material produced by inexperience teachers (software), (2) insufficient development of natural language processing techniques, (3) poor linguistic modeling, and (4) false starts and incomplete realizations of CALL. Levy also maintains the computer's limited ability in handling natural language.

Ravichandran (2000) \& Bollin (2003) argue that language teachers can be more comfortable with traditional textbooks since it is what they are used to do, and there is the idea that the use of computers threatens traditional literacy skills since they are heavily tied to books. They claim that this situation emerged in part because there is indispensible generation gap between teachers (many of whom did not grow up with computers) and students (who did grow up with computers). It is worth mentioning that teachers who are not technologically competent tend to believe that computers are worthless. On the contrary, most teachers who are technologically competent think that computers can facilitate language learning.

Lu \& Powell (2004) propose a methodology to discover the barriers that influence EFL teachers in the use of computers in their classroom. The findings demonstrate that there are three key barriers that influence teachers who use CALL programs to teach EFL. These barriers are: (1) technology skills, (2) funding, and (3) the acceptance of technology.

Obstacles include the quality of the instructional software and the high cost (Bani Hani,2009:5); technophobia (Lam,2000); Thelmadatter (2007); time pressures both outside and during class (Lam, 2000; Levy, 1997; Smerdon, Cronen, Lanahan, Anderson, Iannotti, \& Angeles, 2000; Strudler, Mckinney, \& Jones, (1999); lack of resources \& materials (Loehr, 1996:3), insufficient or inflexible guidelines, standards, and curricula (Langone ,Wissick, Langone, \& Ross, 1998); lack of support or recognition for integrating computers (Grau 1996; Strudler et al, 1999); a clash between new technologies at universities and older ones in schools; lack of leadership (Smerdon et al, 2000:6); and inadequate training and technical support (Levy, 1997; Langone et.al., 1998; Lam, 2000; Smerdon et al, 2000).

To sum up, the disadvantages of inhibiting the implementation of CALL can be classified into the following linchpin, common categories: (1) financial barriers, (2) availability of computer hardware and software, (3) technical and theoretical knowledge, and (4) acceptance of the technology (Bani Hani, 2009:12). The researcher believes that most of the problems that appear in the literature on CALL have to do with teacher expectations and apprehensions about what computers can do for the language learner and teacher. Responding to these criticisms, the researcher believes that designing authentic instructional computer programs may motivate language learning and ease the learning process. It may pave the way for more flexibility, understanding the global role of language and elimination of psychological 
barriers. That is, computerized learning can be achieved inside and outside the classroom in a relaxed atmosphere as it fosters new strategies for learning. For example, it may create room for learner interaction with material. This interaction can be easy and tangible.

The researcher may conclude that using computers facilitate language teaching and learning, as it is hoped that by implementing CALL, foreign language teaching will be more effective and sufficient. In addition, the use of the computer can have a beneficial effect on enhancing students' achievement (Bani Hani, 2009). Moreover, the use of CALL is expected to enhance the development of language skills. The researcher may also conclude that the use of CALL does not eliminate the role of the teacher, as teachers can help students focus on the primary goals of communicating and learning language. CALL can also open up opportunities for teachers and students to experience the world beyond the classroom and open doors to communication, understanding and interaction.

\section{METHODOLOGY}

The population of this study consists of all teachers who teach English in the Ministry of Education in Jordan in the academic year 2013-2014.Most of them (96\%) hold a B.A degree in English Literature. The sample of the study consisted of two hundred English teachers (110) male and (90) female. Almost all (98\%) of the participants in the sample (196) hold a B.A degree in English Literature and know the basics of the computer usage. In addition, 47 of the study sample have passed ICDL (International Computer Driving License) and twenty three of the participants in the sample were MA degree holders.

And since, the overriding question that begs an answer in this research is "What are the advantages and disadvantages of the implementation of CALL in Jordan? This question was distributed to twenty experienced English teachers. The responses were investigated and presented as shown in table 1 below. To guarantee the reliability of the results in the study, the researcher also collected the most significant advantages and disadvantages from the study literature and added them to the list as shown in table 1. As for data collection, the researcher distributed the advantages and the disadvantages to the members of the sample and they were asked to respond (agree) if the respondent thinks it is an advantage and (disagree) if the respondent believes that it is a disadvantage. The respondents were urged to ask for any explanation if there was an ambiguity.

\section{RESULTS AND ANALYSIS}

In this section, the findings are presented and discussed according to the main question in this research which is "what are the advantages and disadvantages of CALL implementation in the Arab world and Jordan?. The advantages and disadvantages are presented in table 1.

TABLE 1

ADVANTAGES AND DISADVANTAGES OF USING CALL IN JORDAN

\begin{tabular}{|c|c|c|c|c|c|c|}
\hline Rank & Advantages & Agree & Disagree & Disadvantages & Agree & Disagree \\
\hline 1. & Providing immediate feedback & $91 \%$ & $9 \%$ & Inadequate number of computers & $96 \%$ & $4 \%$ \\
\hline 2. & Motivating students' learning & $89 \%$ & $11 \%$ & Technical problems & $90 \%$ & $9 \%$ \\
\hline 3. & Exciting and more fun & $87 \%$ & $13 \%$ & Needs more teacher training & $88 \%$ & $12 \%$ \\
\hline 4. & Initiating more interaction & $85 \%$ & $15 \%$ & More time is needed & $81 \%$ & $19 \%$ \\
\hline 5. & Easy to control & $82 \%$ & $18 \%$ & The cost is high & $76 \%$ & $24 \%$ \\
\hline 6. & Needs less time and effort & $81 \%$ & $19 \%$ & Lack of experience in computer & $73 \%$ & $27 \%$ \\
\hline 7. & More participation & $80 \%$ & $20 \%$ & Slow computers & $71 \%$ & $29 \%$ \\
\hline 8. & Integrating of language skills & $77 \%$ & $23 \%$ & Difficult to prepare the lesson & $70 \%$ & $30 \%$ \\
\hline 9. & Fostering individualization & $77 \%$ & $23 \%$ & It may replace the teacher & $65 \%$ & $35 \%$ \\
\hline 10. & Flexible to be used & $76 \%$ & $24 \%$ & The instructions may not be clear & $61 \%$ & $39 \%$ \\
\hline 11. & Providing a new experience & $65 \%$ & $35 \%$ & Lack of well-designed software & $58 \%$ & $42 \%$ \\
\hline 12. & Learning outside the classroom & $65 \%$ & $35 \%$ & The need for continuous updating & $55 \%$ & $45 \%$ \\
\hline 13. & Fostering students' role & $62 \%$ & $38 \%$ & Students deem computer a game & $51 \%$ & $49 \%$ \\
\hline 14. & Providing more activities & $55 \%$ & $45 \%$ & Large number of students in class & $47 \%$ & $53 \%$ \\
\hline 15. & Using new technologies (Internet) & $54 \%$ & $46 \%$ & The inability to control the class & $42 \%$ & $58 \%$ \\
\hline 16. & Helping shy students & $51 \%$ & $49 \%$ & Less chances for weak students & $34 \%$ & $66 \%$ \\
\hline 17. & Exchange experience with others & $43 \%$ & $57 \%$ & Cause physical problems & $27 \%$ & $73 \%$ \\
\hline 18. & Needs less computer skills & $39 \%$ & $61 \%$ & Blind students will not benefit & $22 \%$ & $78 \%$ \\
\hline 19. & Providing animation & $35 \%$ & $65 \%$ & Lack of students' computer skills & $21 \%$ & $79 \%$ \\
\hline
\end{tabular}

Table 1 shows that the major advantages of the use of CALL in TEFL are: (1) immediate feedback, (2) motivation, (3) exciting and more fun (4) interaction, (5) easy to control, (6) needs less time and effort, (7) more participation, (8) the integration of language skills, (9) fostering individualization, (10) flexibility, (11) new experience, and (12) the ability to learn outside the classroom. Table 1 further reveals that the most important disadvantages are: (1) inadequate number of computers, (2) technical problems, (3) needs more teacher training(4) more time is needed (5) the cost (6) lack of the computer experience (7) slow computers (8) difficulty in preparing the lesson(9) may replace the teacher(10) clarity of instructions, (11) lack of well- designed software, and (12) the need for continuous updating. Other less significant 
barriers emerged such as (1) the students consider computer a game, (2) lack of students' skills on the computer, (3) time consuming, (4) more teacher training is needed, and (5) large number of students per class.

The results reveal that teachers consider providing immediate feedback the most important advantage of the utilization of the computer in the English classroom. This is inconsistent with earlier findings (see for example, Zapata, 2004; Bani Hani, 2009). This may be due to the fact that teachers may forget, but computers never. Consequently, the students' motivation will vividly improve which is the second advantage that emerged in this study. As the computer is deemed a mean of entertainment, the respondents consider implementing CALL in the classroom exciting and fun.

Regarding the forth advantage that came into prominence, it is found that implementing CALL may initiate more interaction which will hopefully lead to the utilization of language as a mean for communication. It is worth mentioning that languages have recently been taught to be used as a communication instrument, so using computer as a tool in the classroom may not only be helpful but also beneficial. Along the same lines, some new types of interactions have emerged such as student-computer interaction and computer-student interaction. In addition, class-class interaction and school-school interaction has recently become possible through the use of the computer associated technologies like the internet.

As for the fifth advantage, it is revealed that implementing CALL may help in controlling the classroom activities and practices. Undoubtedly, control in the classroom is necessary to help teachers explain and interpret the lessons properly. In addition, it was found that using CALL in the classroom may save time and effort. One significant motto in teaching is teaching effectively with the least time and effort. Based on this important assumption, the computer may be used to fulfill this goal. Concerning the seventh merit of using computer in teaching, the study results showed that it may lead to more participation. This will lead to more students' involvement in the learning process (Fu, 2013). As a result, the computer and its associated technologies may help to shift from teacher-centered approach to studentcentered approach (Lu, Hou, \& Huang, 2010).

Last but not least, CALL implementation may lead to the integrating of the four skills. Most methodologists have recently claimed that all the four skills (listening, speaking, reading and writing) should be presented to students simultaneously (Almekhlafi, 2010). According to the respondents, the computer can be utilized to achieve this objective. Furthermore, fostering individualization, flexible to be used, providing a new experience, learning outside the classroom, fostering students' role, providing more activities, using new technologies (Internet), helping shy students, exchanging experience with others, needs less computer skills, and providing animation were all considered advantages of CALL implementation in Jordanian schools.

However, despite all these advantages of CALL utilization, there exist some disadvantages the most important of which is the inadequate number of computers. Despite the efforts that are made by the Jordanian government, our schools still suffer from the lack of computers. The subsidization of computers has not yet been enough for the implementation of CALL in our schools.

The second disadvantage that is found in this study is the technical problem. The researcher believes that these problems can be overcome by providing a computer technician for each school. In addition, the respondents complain about the lack of training on the use of computer. This problem can be overcome by providing a course on CALL for student-teachers at universities Zapata, 2004; Thelmadatter, 2007 \& Koua, 2013). As for time, the researcher thinks that the use of CALL adequately may save time and effort. The high cost is emphasized by the respondents as a disadvantage. This is in consistent with earlier findings (see, for example, Wright, 2003; Bani Hani, 2009). This is no doubt true in the Jordanian case. The researcher thinks that implementing CALL can be subsidized by putting a piaster tax on each electricity bill. Regarding the lack of experience this problem can be solved by time. Considering the slowness and the difficulty in preparing the lesson, these problems may be solved by adequate training and intensive practice. Psychologically speaking, teachers deemed the computer as a threatening tool that may replace them which indicates that teachers are afraid of computers i.e they suffer from technophobia (Lam, 2000). The researcher believes that if rapport is not established between the teachers and the computers, utilizing the computer in teaching will not be sufficient, effective and fruitful. As for the classroom instruction, if the computer program is well-designed, this problem will not exist.

Therefore, establishing well-designed digitized instructional programs may be considered the most essential step that should be implemented authentically (Fu, 2013). The lack of these programs may be deemed as an important obstacle of implementing CALL in schools. Continuous updating is the next disadvantage that is cited by the teachers. The researcher believes that as the computer is a machine that frequently needs improving, anything related to it should also be improved. As for the next disadvantage, students have a wrong perception that the computer was invented to be only a game. The time has come to change this perception by persuading them that the computer can be also a useful teaching tool. This can be best achieved practically (Bani Hani, 2009; Al Abdel Halim, 2009). The large number of students per class was considered a disadvantage of CALL implementation. This problem can be overcome by putting every two students on one computer. It has been empirically proven that students when in pairs benefited best from the computer. (Murphy, 2007; Bani Hani, 2009).

\section{Discussions AND CONCLUSIONS}


A lot of research has been reported on the impact of computer utilization on different facets of the educational process (see for example, Tezci, 2011; Fu, 2013; Gee, 2013). However, little research has been conducted to inform us about the merits and demerits of the implementation of CALL in the realm of teaching. Since the use of technology has to be driven by pedagogy, teachers should be urged to assume more responsibility in utilizing the computer to enhance the quality of teaching and learning. Pre service teacher training programs should include compulsory computer training for teachers to acquire optimum levels of knowledge and skills (Al-Ruz \& Khasawneh, 2011; Tezci, 2011; Lin, Houn \& Lin, 2012; Gee, 2013). The present researcher urges scholars to conduct further research on students and teachers need for technology for educational purposes, on the integration of the four skills, on providing cultural context for foreign language learning, on subsidizing the implementation of CALL, on convincing policymakers and parents that the use of the computer is no more supplementary.

\section{REFERENCES}

[1] AbuSeileek, A. \& Abu Sa'aleek, A. (2012). Computer Assisted Language Learning: Merits and Demerits. Language in India 12(4), 23-36.

[2] Al Abdel Halim, A. (2009). Designing a computer-assisted language learning program (CALL) and measuring its effect on Jordanian secondary school students' reading comprehension in English. Unpublished Ph.D dissertation, Yarmouk University, Irbid, Jordan.

[3] Almekhlafi, A. \& Almeqdadi, F. (2010). Teachers' Perceptions of Technology Integration in the United Arab Emirates School Classrooms. Educational Technology \& Society, 13 (1), 165-175.

[4] Almekhlafi, A. (2006). The Effect of computer assisted language learning (CALL) on United Arab Emirates English as a foreign language (EFL) school students achievement and attitude. Journal of Interactive Learning Research 17 (2), 121 - 142.

[5] Al-ruz, J. \& Khasawneh, S. (2011). Jordanian pre service teachers' and technology integration: A human resource development approach, Educational Technology and Society, 14, 77-87.

[6] Bani Hani, N.(2009). Designing an English computerized instructional program for Jordanian sixth grade students and measuring its effect on their achievement. Unpublished Doctoral Dissertation, Yarmouk University, Irbid, Jordan.

[7] Bataineh, R. \& Baniabdelrahman, A. (2006). Jordanian EFL students' perceptions of their computer literacy: an exploratory case study. International Journal of Education and Development Using ICT, 2(2). Retrieved 3 August 2008 from http://ijedict.dec.uwi.edu/\%20viewisse.php/id=8.

[8] Becker, H. (2000). Pedagogical motivations for student computer use that lead to student engagement. Educacional Technology, 40,5-17.

[9] Bollin,G. (2003). The realities of middle school for Mexican children. The Clearing House 76 (4), 198. Retrieved 28 April 2008 from, http://lit.msu.edu/ vol6num1 /pdf/ steppgreany.pdf.

[10] Chen, C. H., 2008. Why do teachers not practice what they believe regarding technology integration? Journal of Educational Research, 102, 65-75.

[11] Fu, J. (2013). ICT in Education: A Critical Literature Review and Its Implications. International Journal of Education and Development using Information and Communication Technology, 9(1), 112-125.

[12] Gee, J. (2013). Language and learning in the digital age. New York : Routledge.

[13] Goldman, S; Cole, K; and Syer, C. (1999). The technology/ content dilemma. paper presented at the secretary's conference on educational technology. $\quad$ Retrieved $\quad$ June $\quad 3 \quad 2008$ from http://www.ed.gov/technology/techConf/1999/whitepapers/\%20paper\%204.html.

[14] Grau, I. (1996). Teacher development in technology instruction: does computer coursework transfer into actual teaching practice? paper presented at the annual meeting of the southwest educational research association, Dallas, Texas (U.S.A). (ERIC Document Reproduction Service No. ED394949).

[15] Han, W. (2008). Benefits and barriers of computer assisted language learning and teaching. US-China Foreign Language, ISSN1539-8080, USA, 6 (9), 40-43.

[16] Jonita, C. (2002). Students' implications for the new millennium. Language learning and technology. Retrieved August 12, 2008, from, http://lit.msu.edu/ vol6num1 /pdf/ steppgreany.pdf.

[17] Koua, V. (2012). The Internet in French Language Teaching and Learning: Positive and Negative Impacts. Theory and Practice in Language Studies, 3(4), 564-571.

[18] Lam, Y. (2000). Technophilia v. technophobia: a preliminary look at why second language teachers do or do not use technology in their classrooms. Canadian Modern Language Review, 56, 389-420.

[19] Langone,C. Wissick, C. Langone, J. and Ross, G. (1998). A study of graduates of a technology teacher preparation program. Journal of Teacher Education, 6(4), 283-302.

[20] Levy, M. (1997). Computer assisted language learning, context and conceptualization. Clarendon Press, Oxford: UK.

[21] Lin, M.-C., Wang, P.-Y. and Lin, I.-C., (2012). Pedagogy technology: A two-dimensional model for teachers' ICT integration, British Journal of Educational Technology, 43, 97-108.

[22] Loehr, M. (1996). Top ten media competency recommendations by teachers for teacher training. Technology and teacher education annual, 474-476.

[23] Lu, Z., Hou, L \& Huang, X., (2010). A research on a student-centered teaching model in an ICT based English audio-video speaking class. International Journal of Education and Development using Information and Communication Technology, 6, 101-123.

[24] Lu, S \& Powell, R. (2004). Language engineering for the semantic web. Information Research. Retrieved August 24, 2008, from http://information.net/ir/9-3/paper176.html.

[25] Murphy, P. (2007). Reading comprehension exercises online: the effects of feedback, proficiency and interaction. Language Learning and Technology, 11(3), 107-129. 
[26] Noemi, D. (2007). Computer-assisted language learning: increase of freedom of submission to machines. Retrieved on December 102008 from, htt://www.terra.es /personal / nostat/.

[27] Ravichandran, T. (2000).Computer-assisted Language Learning (CALL) in the Perspective of the Interactive Approach Advantages and Apprehensions, CALL, 30(4), 1-15.

[28] Riasati, M, Allahyar, N , \& Tan K.(2012). Technology in Language Education: Benefits and Barriers. Journal of Education and Practice, 3(5), 25-30.

[29] Sang, G., Valcke, M., Braak, J., Tondeur, J. \& Zhu, C., (2011). Predicting ICT integration into classroom teaching in Chinese primary schools: Exploring the complex interplay of teacher-related variables. Journal of Computer Assisted Learning, 27, 160172.

[30] Smerdon, B, Cronen, S, Lanahan, L, Anderson, J, Iannotti, N, \& Angeles, J. (2000). Teachers' tools for the $21^{\text {st }}$ century: a report on teachers' use of technology. Washington, DC: National Center for Education Statistics.

[31] Smith, B. (2008). Methodological hurdles in capturing CMC data: the case of the missing self-repair. Language Learning \& Technology 12(1), 85-103.

[32] Strudler, N, Mckinney, S, \& Jones, W. (1999). First-year teachers' use of technology: preparation, expectations and realities. Journal of Technology and Teacher Education, 7(2), 115-129.

[33] Tezci, E., (2011). Factors that influence pre service teachers' ICT usage in education. European Journal of Teacher Education, 34, 483-499.

[34] Thelmadatter, L. (2007). The computers are coming... are here. TESOL. Greece, News letter, 3 (4) 8-18.

[35] Traynor, P. (2003). Effects of CAI on different learners. Journal of Instructional Psychology, 12(2), 25-39.

[36] Turnbull, M \& Lawrence, G. (2002). Computers make sense according to brain research...but what do students think? Canadian Association of Second Language Teachers. Retrieved December 62008 from http://www.caslt.org/.

[37] Wright, S. (2003). Language engineering. Retrieved April 9, 2008, from http:/ appling.kent.edu/ resource page/ T standards/chart/language.html.

[38] Zapata, G. (2004). Second language instructors and CALL: a multidisciplinary research framework. Computer Assisted Language Learning, 17(3, 4), 339 - 356.

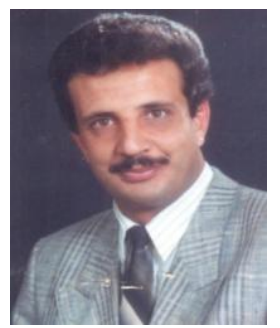

Nedal A. Bani Hani was born in Irbid- Jordan on the $6^{\text {th }}$ of April 1965. The author got his B.A degree in English Language and Literature from Yarmouk University- Irbid- Jordan, 1989. He obtained his M.A degree in Methodology from Yarmouk University - Irbid - Jordan, 1993. The phD degree was obtained in Methodology from Yarmouk University - Irbid- Jordan, 2010. The major of the writer in the phD degree was Computer Assisted Language Learning (CALL).

Dr. Nedal Bani Hani is now the Head of the Department of English Language and Literature at Irbid University College for Girls at Al Balq'a Applied University in Jordan. He has been teaching English language at colleges and universities since 1993. He has published seven articles so far; the most important of which are:

(1) "The Effect of a CALL Program on Jordanian Sixth-Grade Students' Achievement. Teaching English with Technology (Journal of the International Association of Teachers of English as a Foreign Language), 11(3), 3-24, Available on line at http://www.tewtjournal.org//VOL\%201 1/ISSUE3/ ARTICLE1.pdf.

(2)Jordanian EFL students' and teachers' perceptions of the implementation of CALL in TEFL Journal of Instructional Technology and Distance Learning" 9 (12), 3-16. 2012.

(3) Social communication networks....the most powerful present at the service of education" "The Journal of practice and education"21 (4), 2013. 